\title{
Involvement of the fadD33 gene in the growth of Mycobacterium tuberculosis in the liver of BALB/c mice
}

\author{
Laura Rindi, ${ }^{1}$ Lanfranco Fattorini, ${ }^{2}$ Daniela Bonanni, ${ }^{1}$ Elisabetta Iona, ${ }^{2}$ \\ Giulia Freer, ${ }^{1}$ Dejiang Tan, ${ }^{2}$ Gianni Dehò, ${ }^{3}$ Graziella Orefici ${ }^{2}$ \\ and Carlo Garzelli ${ }^{1}$
}

Author for correspondence: C. Garzelli. Tel: +39050 836 559. Fax: +39050836570. e-mail: garzelli@biomed.unipi.it

\footnotetext{
1 Dipartimento di Patologia Sperimentale, Biotecnologie Mediche, Infettivologia ed Epidemiologia, Università di Pisa, I-56127 Pisa, Italy

2 Laboratorio di Batteriologia e Micologia Medica, Istituto Superiore di Sanità, I-00161 Roma, Italy

3 Dipartimento di Genetica e di Biologia dei Microrganismi, Università di Milano, Italy
}

\begin{abstract}
The potential pathogenic role of Mycobacterium tuberculosis H37Rv fadD33, a gene encoding an acyl-CoA synthase that is underexpressed in the attenuated strain H37Ra, was investigated. In a first approach, fadD33 was cloned and expressed in strain H37Ra to restore gene expression and fadD33complemented bacteria were used to investigate whether fadD33 might confer any growth advantage to $M$. tuberculosis H37Ra in an infection model of $B A L B / c$ mice. No differences were found in the growth rates of $M$. tuberculosis H37Rv, H37Ra and fadD33-complemented H37Ra in the lungs and spleen. In contrast, in the liver, where the attenuated strain H37Ra showed impaired growth compared to the virulent strain H37Rv, complementation of the attenuated strain H37Ra with fadD33 restored bacterial replication. In a further approach, the fadD33 gene of strain H37Rv was disrupted by allelic exchange mutagenesis and the virulence of the mutant strain was tested by mouse infection. It was found that disruption of fadD33 decreased $M$. tuberculosis H37Rv growth in the liver, but not in the lungs or spleen, and complementation of the fadD33-disrupted mutant with fadD33 restored bacterial replication in the liver, but did not affect replication in the lungs and spleen. These findings suggest that $\mathrm{fadD} 33$ plays a role in $M$. tuberculosis virulence by supporting bacterial growth in the liver.
\end{abstract}

Keywords: virulence genes, experimental infection

\section{INTRODUCTION}

Although tuberculosis remains one of the leading causes of death worldwide, the mechanisms by which Mycobacterium tuberculosis establishes progressive disease are not well understood. Identification of the virulence factors of M. tuberculosis is of fundamental importance for the development of new vaccines and drugs against this pathogen.

A widely used experimental model for the investigation of M. tuberculosis virulence factors at the gene level is represented by the virulent strain $\mathrm{H} 37 \mathrm{Rv}$ and the attenuated mutant H37Ra, originally derived from the classical M. tuberculosis strain H37 (Steenken et al., 1934). A number of extensive studies have been tried so

Abbreviation: $\mathrm{Kan}^{\mathrm{R}}$, kanamycin-resistance. far to identify the genetic basis for the attenuation of $M$. tuberculosis H37Ra. For example, by transforming $M$. tuberculosis $\mathrm{H} 37 \mathrm{Ra}$ with a cosmid library of $M$. tuberculosis H37Rv, Pascopella et al. (1994) identified a locus that enhanced growth and survival of $M$. $t u$ berculosis $\mathrm{H} 37 \mathrm{Rv}$ in the spleens of infected mice. Furthermore, comparison of M. tuberculosis H37Rv with $M$. tuberculosis H37Ra revealed differences in gene expression (Kinger \& Tyagi, 1993; Rindi et al., 1999; Rivera-Marrero et al., 1998), transposition of insertion elements (Lari et al., 1999, 2001) and genomic polymorphisms and deletions (Brosch et al., 1999), but the reason(s) for the decreased virulence of $M$. tuberculosis $\mathrm{H} 37 \mathrm{Ra}$ have not been determined.

By comparing gene expression of the H37Rv and H37Ra strains by mRNA differential display, Rindi et al. (1999) reported a number of genes that appear to be downregulated in strain H37Ra. Sequences of these genes 
were found only in species belonging to the $M$. tuberculosis complex, i.e. M. tuberculosis, Mycobacterium bovis, including the BCG strain, and $\mathrm{Myco-}$ bacterium microti, thus indicating their association with the most virulent mycobacteria (Rindi et al., 2001). One of these genes, fadD33 (also called Rv1345), is one of 36 homologues of the fadD gene of Escherichia coli identified in the M. tuberculosis genome (Cole et al., 1998). In E. coli, the fadD gene product is an acyl-CoA synthase responsible for the activation of free fatty acids to acyl-CoA thioesters, which represents the first step of fatty acid degradation (Clark \& Cronan, 1996; Nunn, 1987). Predictively, mycobacterial fadD33 encodes an acyl-CoA synthase as well, but the precise biochemical function of FadD33 is not defined at present.

The purpose of the study presented here was to address the question of whether fadD33 plays a role in $M$. tuberculosis infection. For this purpose, we cloned and expressed the fadD33 gene of M. tuberculosis H37Rv in the attenuated strain $\mathrm{H} 37 \mathrm{Ra}$ to restore gene expression; furthermore, we constructed a mutant of strain $\mathrm{H} 37 \mathrm{Rv}$ with a disrupted fadD33 gene. Virulence of fadD33-complemented M. tuberculosis H37Ra and fadD33-disrupted $M$. tuberculosis H37Rv was then tested by experimental mouse infection.

\section{METHODS}

Bacterial strains and growth conditions. M. tuberculosis H37Rv and H37Ra were from a collection maintained at our Department. The IS6110-RFLP patterns of the strains have been reported previously (Lari et al., 1999, 2001) and correspond to genotypes Rv4 and Ra1 of the H37 variants defined by Bifani et al. (2000). The H37Rv and H37Ra strains were grown in liquid Middlebrook 7H9 medium (Difco Laboratories) supplemented with $0.25 \%$ Tween 80 (Difco) and albumin-dextrose complex (ADC) $[0.5 \%$ albumin, fraction V (Sigma), $0 \cdot 085 \% \mathrm{NaCl}, 0 \cdot 2 \%$ glucose]. Middlebrook 7H10 plates supplemented with $10 \%$ OADC enrichment (Becton Dickinson) were used for colony isolation. $M$. tuberculosis H37Rv and H37Ra wild-type strains and recombinant and/or mutant strains used in the present investigation, i.e. H37Ra-fadD33, H37Rv-fadD33:: Kan and fadD33-complemented H37Rv-fadD33: : Kan (see below), grew with similar kinetics in axenic cultures, as determined by the radiometric BACTEC TB 460 system (Becton Dickinson) and by counts of colony-forming units (c.f.u.s) on 7H10 agar plates.

E. coli strains XL-1 Blue, JM109 and DH5 $\alpha$ (Stratagene) were used for recombinant DNA studies and plasmid propagation. These strains were grown on solid or in liquid Luria-Bertani (LB) medium (Sigma). When required, antibiotics were included in the media at the following concentrations: $100 \mu \mathrm{g}$ hygromycin $\mathrm{ml}^{-1}, 20 \mu \mathrm{g}$ kanamycin $\mathrm{ml}^{-1}$ and $5 \mu \mathrm{g}$ gentamicin $\mathrm{ml}^{-1}$ for mycobacteria, and $100 \mu \mathrm{g}$ hygromycin $\mathrm{ml}^{-1}, 50 \mu \mathrm{g}$ kanamycin $\mathrm{ml}^{-1}$ and $20 \mu \mathrm{g}$ gentamicin $\mathrm{ml}^{-1}$ for E. coli.

Recombinant DNA techniques. Extraction of mycobacterial genomic DNA, molecular cloning and restriction endonuclease digestions were performed by standard techniques (Sambrook et al., 1989). Cloning vectors used were pBluescript $\mathrm{KS}(+)$ (Stratagene), pROLHYG, pMY9 and pPR27 (Pelicic et al., 1997). Plasmid pROLHYG was obtained from the shuttle plasmid pHYG16R1 (Garbe et al., 1994) by the addition of the
pBluescript-II-SK polylinker in the KpnI site. Plasmid pMY9 was constructed by cloning the Tn903 aph gene conferring kanamycin-resistance $\left(\mathrm{Kan}^{\mathrm{R}}\right)$ into EcoRI-digested pUC8 (Yanisch-Perron et al., 1985). The $\mathrm{Kan}^{\mathrm{R}}$ cassette was amplified by PCR from pMD31 (Donnelly-Wu et al., 1993) using EcoRItailed primers (5'-GCGAATTCCTTTTCTGTGACTGGTGA-3' and 5'-CGGAATTCTCTCAGAATGACTTGGTTG$\left.3^{\prime}\right)$ and digested with EcoRI. Restriction endonucleases and other enzymes (Roche Molecular Biochemicals) were used according to the manufacturers' instructions.

Cloning of fadD33 and complementation of $\boldsymbol{M}$. tuberculosis H37Ra and the H37Rv-fadD33::Kan mutant. A $1.809 \mathrm{kbp}$ fragment of $M$. tuberculosis H37Rv chromosomal DNA, including the full-length fadD33 gene (GenBank accession no. Q11015; sequence positions 1509281-1510843), was amplified by PCR. Primers PKup (5'-ACGCTGCTGAGGATCCTG-3') and PKlow (5'-CAGCAGCTCCAGCCTAGG-3'), annealing to bases 217-199 upstream (in order to include the promoter) and bases 9-26 downstream of the fadD33 reading frame, respectively, were used. The primers had a base mutation $(\mathrm{C} \rightarrow \mathrm{G}$ and $\mathrm{G} \rightarrow \mathrm{T}$, respectively) to create $\mathrm{BamHI}$ restriction sites. The PCR-generated fragment was cloned in E. coli XL-1 Blue into the E. coli-Mycobacterium shuttle vector pROLHYG, encoding hygromycin resistance, which had been digested with BamHI (Boehringer), according to standard protocols (Sambrook et al., 1989). The resulting plasmid (pROLHYG-fadD33) was propagated in E. coli XL-1 Blue after selection on LB agar containing $100 \mu \mathrm{g}$ hygromycin $\mathrm{ml}^{-1}$ (Sigma). The integrity of the coding region was verified by sequencing the inserted DNA fragment using an automated apparatus (ALFexpress DNA sequencer; Pharmacia Biotech), using the Cy5 Thermo Sequenase dye Terminator Kit (Pharmacia). The recombinant pROLHYG-fadD33 was then used to transform by electroporation $M$. tuberculosis $\mathrm{H} 37 \mathrm{Ra}$ and the H37Rv-fadD33:: Kan mutant (see below). Transformants were selected by growth at $37^{\circ} \mathrm{C}$ on Middlebrook $7 \mathrm{H} 10$ agar containing $100 \mu \mathrm{g}$ hygromycin $\mathrm{B} \mathrm{ml}^{-1}$.

Construction of the $M$. tuberculosis H37Rv-fadD33::Kan mutant. A $2.971 \mathrm{kbp} \mathrm{XbaI-ClaI} \mathrm{fragment} \mathrm{containing} \mathrm{fadD33}$ was cloned in E. coli into pBluescript $\mathrm{KS}(+)$ by standard methods (Sambrook et al., 1989) and a 275 bp intragenic fragment of fadD33 was removed by EcoRI digestion. The EcoRI $1 \mathrm{kbp} \mathrm{Kan}^{\mathrm{R}}$ cassette from pMY9 was inserted at the EcoRI site present in fadD33. The resulting $3.9 \mathrm{kbp} \mathrm{XbaI-SfuI}$ fragment, which contained $1.7 \mathrm{kbp}$ of fadD33 left-flanking DNA and $1.2 \mathrm{kbp}$ of fadD33 right-flanking sequenced around a central $\mathrm{Kan}^{\mathrm{R}}$ gene, was excised and blunt-end cloned into pPR27, a mycobacterial suicide vector carrying gentamicin resistance, sucrose sensitivity and an origin of replication thermosensitive in mycobacteria, to yield pPR27-fadD33:: Kan. Approximately $1 \mu \mathrm{g}$ pPR27-fadD33::Kan was introduced into electrocompetent $M$. tuberculosis H37Rv. Five millilitres of $7 \mathrm{H} 9 /$ ADC broth without antibiotics was added immediately, and the bacteria were incubated at $32{ }^{\circ} \mathrm{C}$ for $24 \mathrm{~h}$. Transformants were selected at $32^{\circ} \mathrm{C}$ on $7 \mathrm{H} 10 /$ kanamycin and were grown in $7 \mathrm{H} 9 /$ kanamycin at $32^{\circ} \mathrm{C}$ until saturation. The cultures were then plated at $39^{\circ} \mathrm{C}$ onto $7 \mathrm{H} 10 /$ kanamycin with $2 \%$ sucrose. PCR analysis was performed to screen for disruption of $\mathrm{fadD} 33$. In particular, primers [PKa (5'-ATGACCGCGGCACCGAACTT-3') and $\mathrm{PKb}\left(5^{\prime}\right.$-GATCCAGGCGACACGAAGAC-3')] that flanked the deletion site were used, producing a $758 \mathrm{bp}$ fragment in the wild-type and a $1483 \mathrm{bp}$ fragment in the deletion strain. The PCR mix contained $10 \mathrm{mM}$ Tris $/ \mathrm{HCl}$ (pH 8.8), $1.5 \mathrm{mM}$ $\mathrm{MgCl}_{2}, 50 \mathrm{mM} \mathrm{KCl}, 0 \cdot 1 \%$ Triton X-100, $250 \mathrm{ng}$ each primer, $0.2 \mathrm{mM}$ each dNTP, 1.25 U Taq polymerase (Dynazyme) and 
10 ng DNA per $50 \mu \mathrm{l}$ of reaction mixture. PCR amplification was performed with an OmniGene temperature cycler $(\mathrm{Hy}-$ baid) set for one cycle of $3 \mathrm{~min}$ at $94^{\circ} \mathrm{C}, 25$ cycles of $1 \mathrm{~min}$ at $94^{\circ} \mathrm{C}, 1 \mathrm{~min}$ at $60^{\circ} \mathrm{C}$ and $2 \mathrm{~min}$ at $72^{\circ} \mathrm{C}$, with a final cycle for $4 \mathrm{~min}$ at $72^{\circ} \mathrm{C}$. Aliquots $(10 \mu \mathrm{l})$ of PCR products were analysed by $2 \%$ agarose gel electrophoresis.

Electrotransformation. M. tuberculosis H37Rv and H37Ra were prepared for electroporation as described by Pelicic $e t$ al. (1997), with minor modifications. Briefly, cells were grown in $200 \mathrm{ml}$ Middlebrook 7H9/ADC/Tween 80 for 3 weeks at $37^{\circ} \mathrm{C}$, washed three times in $10 \%(\mathrm{v} / \mathrm{v})$ glycerol, resuspended in $1 \mathrm{ml}$ of $10 \%$ glycerol and stored at $-80{ }^{\circ} \mathrm{C}$ until needed. Aliquots $(100 \mu \mathrm{l})$ of competent cells were mixed with approximately $1 \mu \mathrm{g}$ recombinant DNA in a Bio-Rad cuvette with a $0.2 \mathrm{~cm}$ gap width and electrotransformed with a BioRad Gene Pulser and Pulse Controller set at $25 \mu \mathrm{F}, 200 \Omega$ and $2.5 \mathrm{kV}$.

Gene expression analysis by RT-PCR. Total RNA was extracted from the pellet of mycobacterial cells growing in liquid Middlebrook medium essentially as described by Chomczynski \& Sacchi (1987) with minor modifications (Rindi et al., 1998). RNA reverse transcription was carried out by using oligo(dT)-primed reverse transcriptase $(\mathrm{RT})$, as described previously (Rindi et al., 1998). Briefly, a $1 \mu \mathrm{g}$ sample of bacterial RNA, dissolved in diethyl pyrocarbonate (DEPC)treated water, was heated at $65^{\circ} \mathrm{C}$ for $15 \mathrm{~min}$ and then cooled on ice before cDNA synthesis. Oligo $(\mathrm{dT})_{15}$ (Pharmacia Biotech) was used to initiate the first strand cDNA synthesis, using $200 \mathrm{U}$ M-MLV RT (Gibco) in a buffer containing $50 \mathrm{mM}$ Tris ( $\mathrm{pH} \mathrm{8.3),} 75 \mathrm{mM} \mathrm{KCl}, 3 \mathrm{mM} \mathrm{MgCl}, 10 \mathrm{mM}$ DTT, $0.5 \mathrm{mM}$ each dNTP, $20 \mathrm{U}$ RNase inhibitor and $25 \mathrm{pmol}$ primer for $1 \mathrm{~h}$ at $37^{\circ} \mathrm{C}$ in a total volume of $20 \mu \mathrm{l}$. The reaction was stopped by incubation at $95^{\circ} \mathrm{C}$ for $5 \mathrm{~min}$. A $175 \mathrm{bp}$ fadD33-specific target sequence of the generated cDNAs was PCR-amplified using oligonucleotide primers PK1 (5'-TGCTTGCCGACCGTGTCATC-3') and PK2 (5'-CCCAGGTAACCCGCCATCAT-3'), which anneal to bases 980-999 (upstream) and bases 1135-1154 (downstream), respectively, of the fadD33 reading frame. Briefly, PCR was performed in $0.5 \mathrm{ml}$ microcentrifuge reaction tubes in a final volume of $50 \mu \mathrm{l}$ containing $10 \mathrm{mM}$ Tris $/ \mathrm{HCl}(\mathrm{pH} 8.8), 1.5 \mathrm{mM} \mathrm{MgCl}_{2}, 50 \mathrm{mM}$ $\mathrm{KCl}, 0 \cdot 1 \%$ Triton $\mathrm{X}-100,250 \mathrm{ng}$ each primer, $0 \cdot 2 \mathrm{mM}$ each dNTP and 1.25 U Taq polymerase (Dynazyme). PCR amplification was performed with an OmniGene temperature cycler (Hybaid) set for one cycle of $3 \mathrm{~min}$ at $94^{\circ} \mathrm{C}, 25$ cycles of $1 \mathrm{~min}$ at $94^{\circ} \mathrm{C}, 1 \mathrm{~min}$ at $60^{\circ} \mathrm{C}$ and $2 \mathrm{~min}$ at $72^{\circ} \mathrm{C}$, with a final cycle of $4 \mathrm{~min}$ at $72^{\circ} \mathrm{C}$. For $R v 0441 \mathrm{c}$ expression studies, a $225 \mathrm{bp}$ specific target of the M. tuberculosis Rv0441c gene encoding the $65 \mathrm{kDa}$ antigen (GenBank accession no. M15467) was PCR-amplified using primers 65K1 (5'-CGGTTCGACAAGGGCTACATC-3') and 65K2 (5'-GCGGATCTTGTTGACGACCAG-3'), as described previously (Rindi et al., 1998). Aliquots $(10 \mu \mathrm{l})$ of the PCR products were analysed by $2 \%$ agarose gel electrophoresis.

Infection of mice. BALB/c male mice (Calco, Como, Italy) were infected intravenously with $0.2 \mathrm{ml}$ aliquots of mycobacterial suspensions containing approximately $1 \times 10^{5}$ c.f.u $(0.2 \mathrm{ml})^{-1}$. At each time point, mice were killed and the number of c.f.u.s in the spleen, lung and liver were determined. Organs were aseptically removed and homogenized in Middlebrook $7 \mathrm{H} 9$ broth. To enumerate c.f.u. values, $0.5 \mathrm{ml}$ aliquots of 10 -fold serial dilutions of homogenates were plated onto Middlebrook 7H10 agar medium and colonies were counted after 3 weeks incubation at $37^{\circ} \mathrm{C}$ in a humidified $5 \% \mathrm{CO}_{2}$ atmosphere. The number of c.f.u.s per entire organ was reported as the $\log _{10}$ value. The significance of the difference in the mean number of c.f.u.s per organ was calculated by the ANOVA test according to the INSTAT software package (GraphPad); all $P$ values less than 0.05 were considered to indicate statistical significance.

\section{RESULTS \\ Cloning of fadD33}

A 1809 bp DNA fragment, including the 1563 bp fadD33 gene and its promoter, was PCR-amplified from $M$. tuberculosis $\mathrm{H} 37 \mathrm{Rv}$ genomic DNA by using a pair of specific primers. The amplified product was cloned in $E$. coli XL-1 Blue into the E. coli-Mycobacterium shuttle expression vector pROLHYG and 60 colonies were examined for the presence of the insert by restriction analysis. Six E. coli transformants, which harboured pROLHYG containing the insert of the expected length, were sequenced. Five of these showed nucleotide sequences with 1-3 single base mutations determining an incorrect fadD33 gene product; one transformant, selected for the present study, showed a nucleotide sequence encoding the expected product of fadD33, although a silent single base mutation $(\mathrm{C} \rightarrow \mathrm{T})$ was found at gene position 430 .

\section{Complementation of $M$. tuberculosis H37Ra}

The recombinant shuttle plasmid pROLHYG-fadD33 was electroporated into $M$. tuberculosis $\mathrm{H} 37 \mathrm{Ra}$ and the expression of fadD33 in these cells was analysed by RTPCR. In particular, total DNase-treated RNA from $M$. tuberculosis H37Ra(pROLHYG-fadD33), M. tuberculosis H37Ra(pROLHYG), M. tuberculosis H37Ra and M. tuberculosis $\mathrm{H} 37 \mathrm{Rv}$ was transcribed into cDNA by using oligo(dT)-primed reverse transcriptase. The reaction products were then probed by PCR employing primers specific for the fadD33 gene and for a constitutively expressed gene, i.e. Rv0441c, which encodes the $65 \mathrm{kDa}$ antigen (Shinnick et al., 1987). The identity of the amplified cDNA obtained by using primers PK1 and PK2 was verified by sequencing. As shown in Fig. 1, fadD33-specific bands were detected for all of the mRNA transcripts; the signal for the fadD33 messenger from strains $\mathrm{H} 37 \mathrm{Ra}$ and $\mathrm{H} 37 \mathrm{Ra}$ (pROLHYG) was markedly weaker than that obtained from $M$. tuberculosis H37Ra(pROLHYG-fadD33) and wild-type H37Rv, while the RNA transcripts for the constitutively expressed $65 \mathrm{kDa}$ antigen gene yielded bands of equivalent intensity in all of the strains.

\section{Mouse infection by fadD33-complemented $M$. tuberculosis H37Ra}

As a first attempt to examine the role of fadD33 on in vivo growth and survival, BALB/c mice were infected intravenously with $M$. tuberculosis $\mathrm{H} 37 \mathrm{Rv}$, M. tuberculosis H37Ra and fadD33-complemented H37Ra. The mice were killed at 1, 21 and 42 days post-infection, and the number of c.f.u.s in the lungs, spleen and liver were 


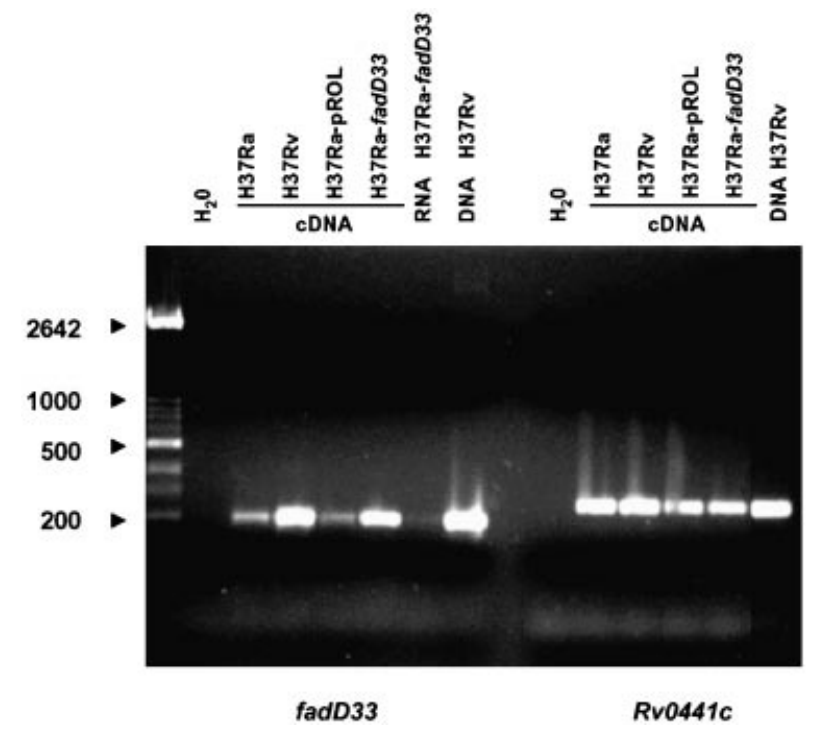

Fig. 1. Expression of $\mathrm{fadD} 33$ in fadD33-complemented $M$. tuberculosis H37Ra. The image shows an ethidium-bromidestained gel of the RT-PCR products, separated by $2 \%$ agarose gel electrophoresis, which were obtained from RNA extracted from M. tuberculosis H37Ra, H37Rv, H37Ra electroporated with pROLHYG (H37Ra-pROL) and H37Ra electroporated with pROLHYG-fadD33 (H37Ra-fadD33) and probed for CDNA of fadD33 and Rv0441c (indicated at the bottom). Lanes also include a molecular mass marker (100 bp ladder), PCR carried out in the absence of CDNA $\left(\mathrm{H}_{2} \mathrm{O}\right)$, RT-PCR products of RNA from $M$. tuberculosis H37Ra-fadD33 (RNA H37Ra-fadD33) and PCR products of DNA from M. tuberculosis H37Rv (DNA H37Rv).

determined (Fig. 2). As to virulent M. tuberculosis H37Rv, the number of c.f.u.s increased by approximately $1 \log _{10}$ in the spleen, $1.5 \log _{10}$ in the lung and $0.5 \log _{10}$ in the liver during the first 3 weeks of infection. Thereafter, the bacillary load stabilized at approximately $10^{5 \cdot 5}$ c.f.u.s in the three organs. In the lungs and spleen, the $\log _{10}$ c.f.u. counts of strain H37Ra, as well as those of the fadD33-complemented H37Ra, were comparable to $\mathrm{H} 37 \mathrm{Rv}$ at any tested time, which might indicate that the H37Rv strain employed in our experiments is not as virulent as expected. In the liver, however, the $\log _{10}$ c.f.u. counts for strain H37Ra were significantly lower than those for strain $\mathrm{H} 37 \mathrm{Rv}$ at 21 and 42 days post-infection $(P<0 \cdot 001)$, and those of the fadD33-complemented H37Ra strain were significantly higher than those of strain H37Ra $(P<0 \cdot 01)$, and not statistically different from strain H37Rv. No animal deaths were recorded during the whole experimental period. These results demonstrate that complementation of strain H37Ra with fadD33 conferred a growth advantage to the attenuated strain H37Ra in the liver.

\section{Construction of the $M$. tuberculosis H37Rv- fadD33:: Kan mutant}

A fragment of the fadD33 gene of M. tuberculosis $\mathrm{H} 37 \mathrm{Rv}$ was replaced with a $\mathrm{Kan}^{\mathrm{R}}$ gene by allelic exchange using $t s-s a c B$ counterselection technology
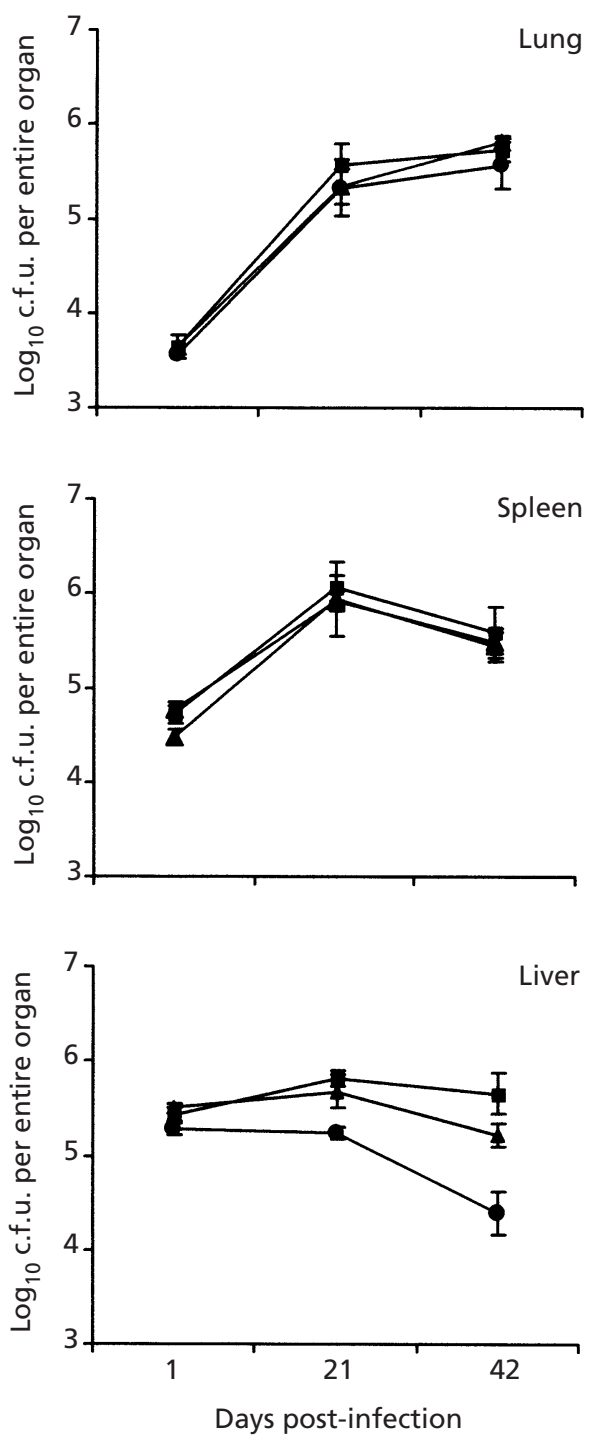

Fig. 2. Experimental infection of $B A L B / C$ mice with $M$. tuberculosis H37Rv (ם), M. tuberculosis H37Ra (O) and $M$.

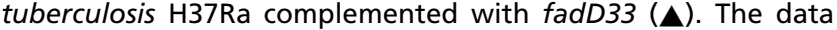
are expressed as the geometric means $\pm S D$ of the $\log _{10}$ c.f.u. counts obtained from four mice per group per time point.

(Pelicic et al., 1997). The recombinant plasmid pPR27fadD33::Kan was introduced into M. tuberculosis $\mathrm{H} 37 \mathrm{Rv}$ by electroporation, and transformants were selected at $32{ }^{\circ} \mathrm{C}$ on $7 \mathrm{H} 10 /$ kanamycin. Several transformants were grown in liquid culture and then plated at $39^{\circ} \mathrm{C}$ onto $7 \mathrm{H} 10 /$ kanamycin containing $2 \%$ sucrose. Various colonies were grown in $7 \mathrm{H} 9$ medium and genomic DNA was extracted and analysed by PCR using a pair of primers flanking the deletion site (Fig. 3). M. tuberculosis H37Rv DNA, which was included as a control, showed one amplification band of $753 \mathrm{bp}$ in size. As expected for allelic exchange mutants, all of the clones presented a single fragment approximately $700 \mathrm{bp}$ longer than that in the wild-type strain. This $700 \mathrm{bp}$ increase corresponded to the size of the $\mathrm{Kan}^{\mathrm{R}}$ gene 


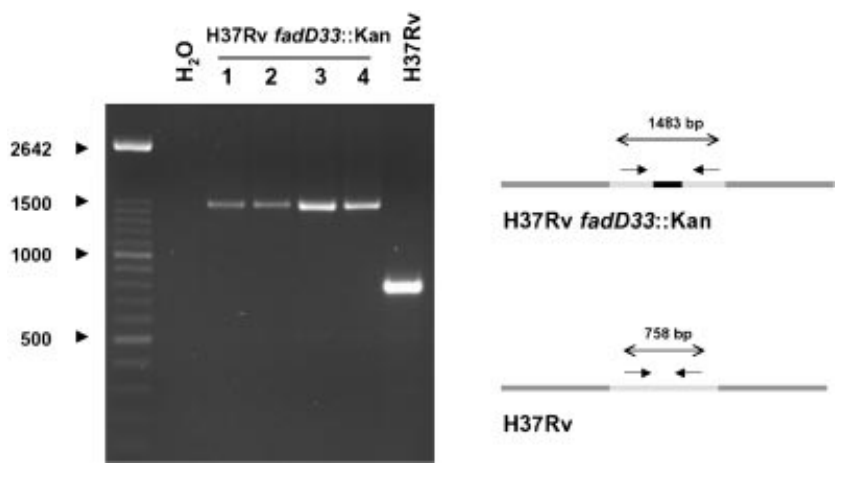

Fig. 3. $f a d D 33$ region in $M$. tuberculosis allelic exchange mutants (H37Rv-fadD33::Kan). (Left panel) PCR products obtained from DNA of four clones of H37Rv-fadD33::Kan mutants (lanes 1-4) and wild-type H37Rv. Lanes also include a molecular mass marker (100 bp ladder) and PCR carried out in the absence of $c D N A\left(\mathrm{H}_{2} \mathrm{O}\right)$. (Right panel) The fadD33 region of the $M$. tuberculosis H37Rv-fadD33::Kan mutant and $M$. tuberculosis H37Rv is outlined. Dark-grey, light-grey and solid bars represent the bacterial chromosome, the fadD33 gene and the $\mathrm{Kan}^{\mathrm{R}}$ box, respectively. The arrows indicate the PCR primer positions; the expected amplicon sizes are also shown.

(1 kbp) that was inserted in place of a $275 \mathrm{bp}$ fragment of the $f a d D 33$ gene. The wild-type and mutant strains of M. tuberculosis $\mathrm{H} 37 \mathrm{Rv}$ showed similar colony morphology, growth characteristics and drug susceptibility profiles (data not shown).

As a control, the M. tuberculosis H37Rv-fadD33:: Kan mutant was complemented with fadD33 by electroporation with the recombinant plasmid pROLHYGfadD33 (as described above). The expression of fadD33 in these cells was analysed by an oligo(dT)-primed RTPCR assay (Rindi et al., 1998). For this purpose, total DNase-treated RNA from M. tuberculosis H37RvfadD33::Kan, M. tuberculosis H37Rv-fadD33:: Kan(pROLHYG-fadD33) and M. tuberculosis H37Rv was transcribed into cDNA by using oligo(dT)-primed reverse transcriptase. The reaction products were then probed by PCR employing primers specific for the fadD33 and Rv0441c genes. Sequence-verified fadD33specific bands were detected for the mRNA transcripts of M. tuberculosis H37Rv-fadD33:: Kan(pROLHYGfadD33) and M. tuberculosis H37Rv, but not from $M$. tuberculosis H37Rv-fadD33: : Kan; the RNA transcripts for $R v 0441 c$ yielded the expected bands in all of the strains (Fig. 4).

\section{Mouse infection by the M. tuberculosis H37Rv- fadD33: Kan mutant}

$\mathrm{BALB} / \mathrm{c}$ mice were infected intravenously with $M$. tuberculosis H37Rv, M. tuberculosis H37Rv-fadD33:: Kan mutant and M. tuberculosis H37Rv-fadD33::


the lungs, spleen and liver at various time points postinfection was determined. In the representative experiment reported in Fig. 5, although the counts of the

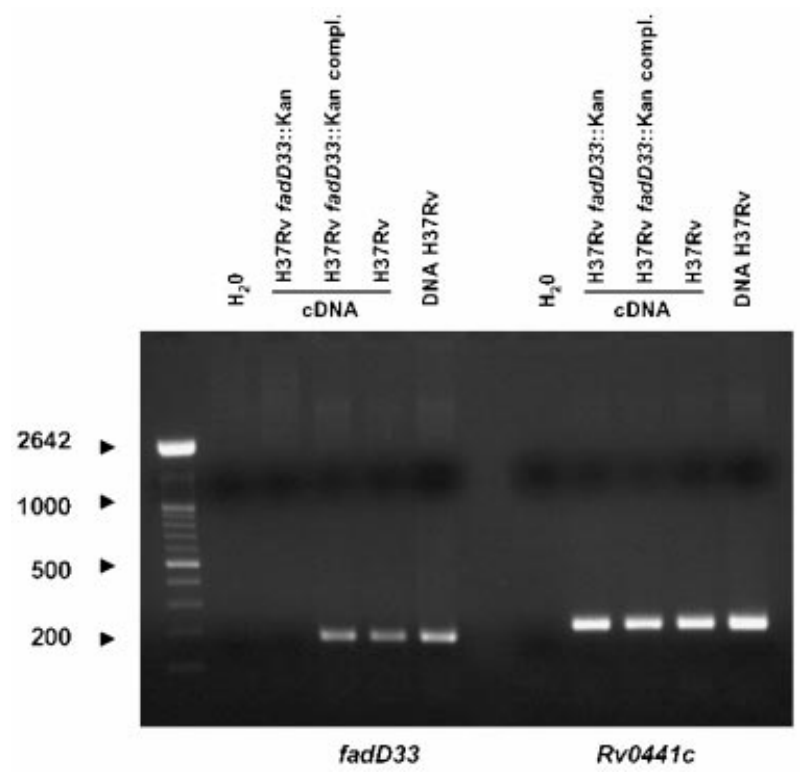

Fig. 4. Expression of $\operatorname{fad} D 33$ in the $M$. tuberculosis H37RvfadD33::Kan and fadD33-complemented H37Rv-fadD33::Kan mutants. The image shows an ethidium-bromide-stained gel of the RT-PCR products that were obtained from RNA extracted from the $M$. tuberculosis H37Rv-fadD33::Kan mutant (H37RvfadD33::Kan), fadD33-complemented H37Rv-fadD33::Kan (H37Rv-fadD33::Kan compl.) and wild-type $M$. tuberculosis H37Rv (H37Rv), and probed for cDNA of fadD33 and Rv0441c (indicated at the bottom). Lanes also include a molecular mass marker (100 bp ladder), PCR carried out in the absence of CDNA $\left(\mathrm{H}_{2} \mathrm{O}\right)$ and PCR products of DNA from $M$. tuberculosis H37Rv (DNA H37Rv).

inocula yielded the expected numbers of c.f.u.s (approx. $10^{5}$ ), the mean number of c.f.u.s of the M. tuberculosis H37Rv-fadD33::Kan mutant found in the spleen at 1 day post-injection was almost $0.4 \log _{10}$ lower than that of the other strains injected, while it did not differ significantly from the other strains in the lungs and liver. At 14, 42 and 123 days post-infection, the c.f.u. counts of the strains tested were comparable in the lungs and spleen, while the number of c.f.u.s of the M. tuberculosis H37Rv-fadD33:: Kan mutant was approximately 0.5 to $0.7 \log _{10}$ lower than those of the parent strain H37Rv in the liver $(P<0.02$ at least, by ANOVA). Notably, in the liver, the c.f.u. numbers of the M. tuberculosis H37RvfadD33:: Kan mutant complemented with fadD33 were significantly higher $\left(0 \cdot 6-1 \log _{10}\right)$ than those of the fadD33-disrupted mutant at 14, 42 and 123 days postinfection $(P<0 \cdot 01$, at least $)$ and similar to those of strain H37Rv. No animal deaths were recorded during the whole experimental period. In another preliminary experiment, the survey of the c.f.u. counts in the organs of infected mice was done at 1, 14, 21 and 42 days postinfection, with results comparable to those reported above. Taken together, our findings indicate that disruption of fadD33 influences the growth of $M$. tuberculosis $\mathrm{H} 37 \mathrm{Rv}$ in the liver, but not in the lungs and spleen. 

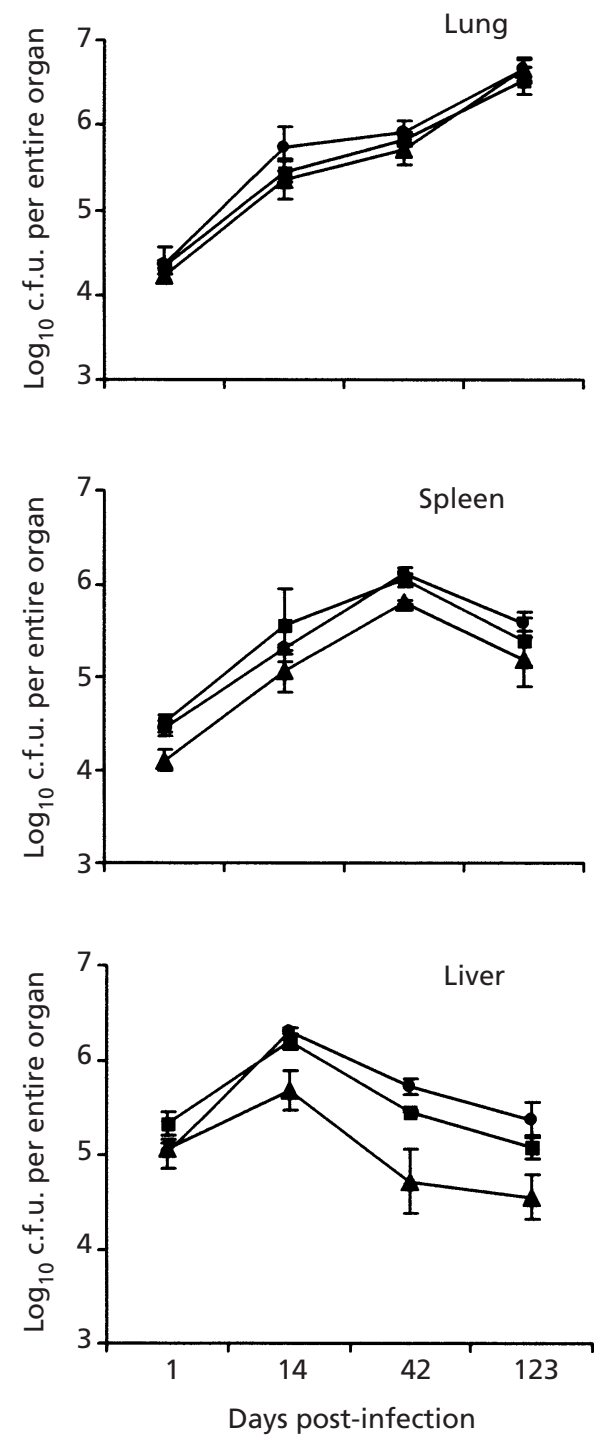

Fig. 5. Experimental infection of $B A L B / C$ mice with $M$. tuberculosis H37Rv ( $\boldsymbol{\square})$, the M. tuberculosis H37Rv-fadD33::Kan mutant ( $\boldsymbol{\Delta}$ ) and the $M$. tuberculosis H37Rv-fadD33::Kan mutant complemented with fadD33 (0). The data are expressed as the geometric means \pm SD of the $\log _{10}$ c.f.u. counts obtained from four to eight mice per group per time point.

\section{DISCUSSION}

In the present study, we have investigated the potential pathogenic role of fadD33, a gene of $M$. tuberculosis that is underexpressed in H37Ra, the attenuated strain derived from $\mathrm{H} 37$.

As a first step, we tested the possibility that restoration of fadD33 expression in strain H37Ra might confer growth advantages in a mouse infection model. These experiments showed that complementation of strain H37Ra with fadD33 restored its replication to the levels of $\mathrm{H} 37 \mathrm{Rv}$ in the liver, but not in the lungs and spleen, where the c.f.u. counts were the same for strains H37Ra and H37Rv.
We then used a further experimental approach to test the role of fadD33 in M. tuberculosis virulence. We prepared a fadD33-disrupted M. tuberculosis H37Rv mutant and the relative fadD33-complemented control, and tested them by mouse infection. This approach confirmed the involvement of $\mathrm{fadD} 33$ in the growth of M. tuberculosis $\mathrm{H} 37 \mathrm{Rv}$ in the liver of $\mathrm{BALB} / \mathrm{c}$ mice. Indeed, disruption of $f a d D 33$ reduced the growth of $M$. tuberculosis $\mathrm{H} 37 \mathrm{Rv}$ in the liver, but not in the lungs and spleen; moreover, complementation of the fadD33disrupted mutant with fadD33 completely restored bacterial replication in the liver.

An unexpected finding in infection experiments (Fig. 2) was that strains $\mathrm{H} 37 \mathrm{Rv}$ and $\mathrm{H} 37 \mathrm{Ra}$ replicated to a comparable extent in the lungs and spleen of infected $\mathrm{BALB} / \mathrm{c}$ mice, although they differed significantly in the liver. Indeed, M. tuberculosis H37Rv would be expected to grow rapidly in immunocompetent mice (more than a $2 \log _{10}$ increase in the c.f.u. count) in the lungs and spleen in the first $2-3$ weeks post-infection. The low rate of replication of M. tuberculosis H37Rv in our experiments might indicate that the strain we used is not as virulent as others, as also suggested by the results from in vitro experiments aimed at investigating the growth of strains H37Rv and H37Ra in human phagocytes. In fact, while $M$. tuberculosis $\mathrm{H} 37 \mathrm{Rv}$ was expected to grow significantly faster than H37Ra in human macrophages (McDonough et al., 1993; North \& Izzo, 1993; Zhang et al., 1998), in our hands, strains H37Rv and H37Ra showed comparable growth in human peripheral blood monocytes; in activated monocytederived THP-1 cells, H37Rv was slightly more resistant than H37Ra to intracellular killing, as judged by the higher number of c.f.u.s detected in cell lysates 2 days post-infection, but grew intracellularly at the same rate as H37Ra thereafter (L. Rindi, unpublished observations). The relatively low rate of replication of our $M$. tuberculosis $\mathrm{H} 37 \mathrm{Rv}$ strain in organs of infected mice and in cultured macrophages might be due to the fact that the strain had not been recently passaged in vivo nor in macrophages in vitro; alternatively, it is also possible that the Rv4 genotype of $H 37 \mathrm{Rv}$, the variant that we employed in our study (Bifani et al., 2000), is actually poorly virulent for BALB/c mice, a strain considered highly resistant to M. tuberculosis (Medina \& North, 1998), as well as being only moderately able to grow within macrophages.

Taken together, the experiments employing the fadD33complemented H37Ra and fadD33-disrupted H37Rv mutants point to the conclusion that $f a d D 33$ plays a role in $M$. tuberculosis virulence in mice by supporting bacterial growth in the liver. The involvement of mycobacterial fadD genes in M. tuberculosis tropism is not unprecedented. In fact, it has been reported that the products of genes fadD26 and fadD28 participate in the biosynthesis of phthiocerol dimycocerosate, a complex cell-wall-associated lipid found only in pathogenic mycobacteria (Brennan \& Nikaido, 1995; Kolattukudy et al., 1997), which determines tissue-specific replication in the lungs (Camacho et al., 1999; Cox et al., 1999). The 
reasons why fadD33 expression might influence $M$. tuberculosis growth in the mouse liver are unknown at present. However, one has to consider that there are 36 fadD genes encoding proteins with acyl-CoA synthase activity in M. tuberculosis $\mathrm{H} 37 \mathrm{Rv}$ and the same number of fadE genes encoding putative acyl-CoA dehydrogenases (Cole et al., 1998). It is therefore likely that such a large number of $\mathrm{fadD} / \mathrm{fadE}$ genes in the M. tuberculosis genome reflects the necessity of $M$. tuberculosis to load a large variety of lipids onto CoA, some of which have to be transported to specific enzymes for lipid degradation and others of which have to be used for biosynthesis. As fadD33 is located just upstream of fadE14 and downstream of an acyl carrier protein gene $(R v 1344)$ in the H37Rv genome (Cole et al., 1998), it may be hypothesized that, after intracellular transport, the proteins FadD33 and FadE14 participate in the activation and subsequent oxidation of liver-specific fatty acids needed as a source of carbon and energy by M. tuberculosis; the products of these enzymes would be then oxidized further in the two pathways required for fatty acid metabolism in bacteria, i.e. $\beta$-oxidation and the glyoxylate shunt (Clark \& Cronan, 1996). The importance of fatty acid metabolism in M. tuberculosis experimental infection in mice has been underscored by McKinney et al. (2000) and Sharma et al. (2000), who showed that isocitrate lyase, one of the glyoxylate shunt enzymes, plays a pivotal role for survival of $M$. tuberculosis in the lungs of mice during the persistent phase of infection, entailing a metabolic shift in the carbon source to two-carbon compounds generated by $\beta$-oxidation of fatty acids.

Alternatively to a role in the degradation of fatty acids, the enzyme FadD33 might participate, similarly to FadD26 and FadD28 in the lungs (Cox et al., 1999), in the biosynthesis of lipids or other metabolites specifically required for growth of M. tuberculosis in the liver of infected mice. Recently, it has been shown that some fad and $f a d D$ genes are induced in M. tuberculosis following detergent-induced surface stress (Manganelli et al., 2001), which might suggest a possible role of their products in the biosynthesis of cell-wall lipids. In this context, we also have to consider that FadD33 is similar to the putative polyketide biosynthesis protein PKSJ of Bacillus subtilis (Albertini et al., 1995), as it shows a $27 \cdot 1 \%$ identity in an overlap of 468 aa (http:// genolist.pasteur.fr/TubercuList/). As microbial polyketide metabolites have shown potent biological activities in different models, acting as virulence factors, antibiotics, immunosuppressants and toxins (George et al., 1999; Kolattukudy et al., 1997; Motamedi et al., 1997), it is tempting to consider that mycobacterial FadD33 might be involved in the synthesis of polyketides that play a role in M. tuberculosis infection in the liver. The involvement of certain polyketide metabolites in $M$. tuberculosis infection has been reported by Graham \& Clark-Curtiss (1999), who showed that pks2, one of the 18 polyketide synthase genes of $M$. tuberculosis $\mathrm{H} 37 \mathrm{Rv}$, is expressed in infected human macrophages but not in bacteria growing in culture broth, and by De Voss et al.
(2000), who demonstrated that the mycobactin siderophores produced by polyketide synthase enzymes are essential for M. tuberculosis growth in macrophages.

Analyses of the lipid profiles of strains $\mathrm{H} 37 \mathrm{Rv}$ and $\mathrm{H} 37 \mathrm{Ra}$, as well as the definition of the cellular localization of the $f a d D 33$ gene product, are likely to provide insights into understanding the precise biochemical function of FadD33 and its role in M. tuberculosis infection.

\section{ACKNOWLEDGEMENTS}

We wish to thank Drs B. Gicquel and C. Sala for providing us with plasmids pPR27 and pMY9, respectively. This work was supported by National Research Program on AIDS grant nos 50A.0.13, 50B.20 and 50C.11 from the Italian 'Istituto Superiore di Sanità', and grant no. ICS 120.5/RF99.96 from the Italian 'Ministero della Sanita'.

\section{REFERENCES}

Albertini, A. M., Caramori, T., Scoffone, F., Scotti, C. \& Galizzi, A. (1995). Sequence around the $159^{\circ}$ region of the Bacillus subtilis genome: the pksX locus spans $33.6 \mathrm{~kb}$. Microbiology 141, 299-309.

Bifani, P., Moghazeh, S., Shopsin, B., Driscoll, J., Ravikovitch, A. \& Kreiswirth, B. N. (2000). Molecular characterization of Mycobacterium tuberculosis $\mathrm{H} 37 \mathrm{Rv} / \mathrm{Ra}$ variants: distinguishing the mycobacterial laboratory strain. J Clin Microbiol 38, 3200-3204.

Brennan, P. J. \& Nikaido, H. (1995). The envelope of mycobacteria. Annu Rev Biochem 64, 29-63.

Brosch, R., Philipp, W. J., Stavropoulos, E., Colston, M. J., Cole, S. T. \& Gordon, S. V. (1999). Genomic analysis reveals variation between Mycobacterium tuberculosis H37Rv and the attenuated M. tuberculosis H37Ra strain. Infect Immun 67, 5768-5774.

Camacho, L. R., Ensergueix, D., Perez, E., Gicquel, B. \& Guilhot, C. (1999). Identification of a virulence gene cluster of Mycobacterium tuberculosis by signature-tagged trasposon mutagenesis. Mol Microbiol 34, 257-267.

Chomczynski, P. \& Sacchi, N. (1987). Single-step method of RNA isolation by acid ganidinium thiocyanate-phenol-chloroform extraction. Anal Biochem 162, 156-159.

Clark, D. P. \& Cronan, J. E., Jr (1996). Two-carbon compounds and fatty acids as carbon sources. In Escherichia coli and Salmonella: Cellular and Molecular Biology, 2nd edn, pp. 343-357. Edited by F. C. Neidhardt and others. Washington, DC: American Society for Microbiology.

Cole, S. T., Brosch, R., Parkhill, J. \& 39 other authors. (1998). Deciphering the biology of Mycobacterium tuberculosis from the complete genome sequence. Nature 393, 537-544.

Cox, J. S., Chen, B., McNeil, M. \& Jacobs, W. R., Jr (1999). Complex lipid determines tissue-specific replication of Mycobacterium tuberculosis in mice. Nature 402, 79-83.

De Voss, J. J., Rutter, K., Schoeder, B. G., Su, H., Zhu, Y. \& Barry, C. E., III (2000). The salicylate-derived mycobactin siderophores of Mycobacterium tuberculosis are essential for growth in macrophages. Proc Natl Acad Sci US A 97, 1252-1257.

Donnelly-Wu, M. K., Jacobs, W. R., Jr \& Hatfull, G. F. (1993). Superinfection immunity of mycobacteriophage L5: applications for genetic transformation of mycobacteria. Mol Microbiol 7, 407-17.

Garbe, T. R., Barathi, J., Barnini, S., Zhang, Y., Abou-Zeid, C., Tang, D., Mukherjee, R. \& Young, D. B. (1994). Transformation of 
mycobacterial species using hygromycin resistance as selectable marker. Microbiology 140, 133-138.

George, K. M., Chatterjee, D., Gunawardana, G., Welty, D., Hayman, J., Lee, R. \& Small, P. L. (1999). Mycolactone: a polyketide toxin from Mycobacterium ulcerans required for virulence. Science 283, 854-857.

Graham, J. E. \& Clark-Curtiss, J. E. (1999). Identification of Mycobacterium tuberculosis RNAs synthesized in response to phagocytosis by human macrophages by selective capture of transcribed sequences (SCOTS). Proc Natl Acad Sci U S A 96, 11554-11559.

Kinger, A. K. \& Tyagi, J. S. (1993). Identification and cloning of genes differentially expressed in the virulent strain of Mycobacterium tuberculosis. Gene 131, 113-117.

Kolattukudy, P. E., Fernandes, N. D., Azad, A. K., Fitzmaurice, A. M. \& Sirakova, T. D. (1997). Biochemistry and molecular genetics of cell-wall lipid biosynthesis in mycobacteria. Mol Microbiol 24, 263-270.

Lari, N., Rindi, L., Lami, C. \& Garzelli, C. (1999). IS6110-based restriction fragment length polymorphism (RFLP) analysis of Mycobacterium tuberculosis H37Rv and H37Ra. Microb Pathog 26, 281-286.

Lari, N., Rindi, L. \& Garzelli, C. (2001). Identification of one insertion site of IS6110 in Mycobacterium tuberculosis H37Ra and analysis of the RvD2 deletion in M. tuberculosis clinical isolates. J Med Microbiol 50, 805-811.

Manganelli, R., Voskuil, M. I., Schoolnik, G. K. \& Smith, I. (2001). The Mycobacterium tuberculosis ECF sigma factor $\sigma^{\mathrm{E}}$ : role in global gene expression and survival in macrophages. Mol Microbiol 41, 423-437.

McDonough, K. A., Kress, Y. \& Bloom, B. R. (1993). Pathogenesis of tuberculosis: interaction of Mycobacterium tuberculosis with macrophages. Infect Immun 61, 2763-2773.

McKinney, J. D., Höner zu Bentrup, K., Muòoz-Elias, E. J. \& 7 other authors (2000). Persistence of Mycobacterium tuberculosis in macrophages and mice requires the glyoxylate shunt enzyme isocitrate lyase. Nature 406, 735-738.

Medina, E. \& North, R. J. (1998). Resistance ranking of some common inbred mouse strains to Mycobacterium tuberculosis and relationship to major histocomatibility complex haplotype and Nramp1 genotype. Immunology 93, 270-274.

Motamedi, H., Cai, S. J., Shafiee, A. \& Elliston, K. O. (1997). Structural organization of a multifunctional polyketide synthase involved in the biosynthesis of the macrolide immunosuppressant FK506. Eur J Biochem 244, 74-80.

North, R. J. \& Izzo, A. A. (1993). Mycobacterial virulence. Virulent strains of Mycobacterium tuberculosis have faster in vivo doubling times and are better equipped to resist growth-inhibiting functions of macrophages in the presence and absence of specific immunity. J Exp Med 177, 1723-1733.
Nunn, W. D. (1987). Two-carbon compounds and fatty acids as carbon sources. In Escherichia coli and Salmonella: Cellular and Molecular Biology, pp. 285-301, 2nd edn. Edited by F. C. Neidhardt and others. Washington, DC: American Society for Microbiology.

Pascopella, L., Collins, F. M., Martin, J. M., Lee, M. H., Hatfull, G. F., Stover, C. K., Bloom, B. R. \& Jacobs, W. R., Jr (1994). Use of in vivo complementation in Mycobacterium tuberculosis to identify a genomic fragment associated with virulence. Infect Immun 62, 1313-1319.

Pelicic, V., Jackson, M., Reyrat, J.-M., Jacobs, W. R., Gicquel, B. \& Guilhot, C. (1997). Efficient allelic exchange and transposon mutagenesis in Mycobacterium tuberculosis. Proc Natl Acad Sci US A 94, 10955-10960.

Rindi, L., Lari, N., Gil, M. G. \& Garzelli, C. (1998). Oligo(dT)primed synthesis of cDNA by reverse transcriptase in mycobacteria. Biochem Biophys Res Commun 248, 216-218.

Rindi, L., Lari, N. \& Garzelli, C. (1999). Search for genes potentially involved in Mycobacterium tuberculosis virulence by mRNA differential display. Biochem Biophys Res Commun 258, 94-101.

Rindi, L., Lari, N. \& Garzelli, C. (2001). Genes of Mycobacterium tuberculosis $\mathrm{H} 37 \mathrm{Rv}$ downregulated in the attenuated strain H37Ra are restricted to M. tuberculosis complex species. New Microbiol 24, 289-294.

Rivera-Marrero, C. A., Burroughs, M. A., Masse, R. A., Vannberg, F. O., Leinbach, D. L., Roman, J. \& Murtagh, J. J., Jr (1998). Identifications of genes differentially expressed in Mycobacterium tuberculosis by differential display PCR. Microb Pathog 25, 307-316.

Sambrook, J., Fritsch, E. F. \& Maniatis, T. (1989). Molecular Cloning: a Laboratory Manual, 2nd edn. Cold Spring Harbor, NY : Cold Spring Harbor Laboratory.

Sharma, V., Sharma, S., Hoener zu Bentrup, K., McKinney, J. D., Russell, D. G., Jacobs, W. R., Jr \& Sacchettini, J. C. (2000). Structure of isocitrate lyase, a persistence factor of Mycobacterium tuberculosis. Nat Struct Biol 7, 663-668.

Shinnick, T. M. (1987). The 65-kilodalton antigen of Mycobacterium tuberculosis. J Bacteriol 169, 1080-1088.

Steenken, W., Jr, Oatway, W. H., Jr \& Petroff, S. A. (1934). Biological studies of the tubercle bacillus. III. Dissociation and pathogenicity of the $\mathrm{R}$ and $\mathrm{S}$ variants of the human tubercle bacillus (H37). J Exp Med 60, 515-540.

Yanisch-Perron, C., Vieira, J. \& Messing, J. (1985). Improved M13 phage cloning vectors and host strains: nucleotide sequences of the M13mp18 and pUC19 vectors. Gene 33, 103-119.

Zhang, M., Gong, J., Lin, Y. \& Barnes, P. F. (1998). Growth of virulent and avirulent Mycobacterium tuberculosis strains in human macrophages. Infect Immun 66, 794-799.

Received 6 June 2002; revised 9 September 2002; accepted 12 September 2002. 